\title{
VARIATIONS IN TENSION WOOD OF TWO BROAD-LEAVED TREE SPECIES IN RESPONSE TO DIFFERENT MECHANICAL TREATMENTS: IMPLICATIONS FOR DENDROCHRONOLOGY AND MASS MOVEMENT STUDIES
}

\author{
Ingo Heinrich ${ }^{1, *}$ and Holger Gärtner† \\ *Department of Geosciences, Geography, University of Fribourg, 1700 Fribourg, Switzerland; and \\ †Swiss Federal Research Institute WSL, Zürcherstrasse 111, 8903 Birmensdorf, Switzerland
}

\begin{abstract}
Reaction wood formation, in particular compression wood in conifers, has often been used to date geomorphic events such as debris flows or snow avalanches. However, very little is known yet about the variations of tension wood formation and particularly cross-sectional vessel characteristics in response to different mechanical impacts. To test whether different intensities and characteristic forms of tension wood formation induce the formation of vessels with changing sizes, growth experiments with different treatments were conducted with alder and beech followed by wood anatomical analysis of the vessels. The experiments comprised bending treatments of varying severities in combination with cambium wounding and other alterations. The treatments were successful in inducing different intensities in tension wood expressed by variations of vessel lumen area (VLA). An increasing bending stress resulted in the formation of lower VLA values. When the apex or the root system was damaged or the apex remained vertical, VLA values decreased less and the tension wood formation was regarded as less intense. Our research shows that VLA is affected by mechanical impacts and that the application of wood anatomical techniques can potentially provide supplementary information about type and intensities of past mechanical impacts in angiosperm tree growth.
\end{abstract}

Keywords: Alnus glutinosa, artificial inclination, dendrochronology, Fagus sylvatica, tension wood, vessel lumen area.

\section{Introduction}

Environmental changes and geomorphic events often have distinct impacts on trees and leave sustained signals in the wood (Schweingruber 1996), which are manifested as variations in tree-ring widths as well as chemical and structural contents of the tree rings, e.g., changing isotopic composition and varying vessel sizes (Fritts 1976; Leavitt 1993; Sass and Eckstein 1995). Tree rings have been used to reconstruct climate, other environmental variables, and geomorphic processes such as landslides, debris flows, and snow avalanches (Alestalo 1971).

Various dendroecological techniques have been developed to date and determine the frequencies of such events. The macroscopic attributes commonly used are changes from concentric to eccentric growth rings, the onset of reaction wood formation, and dating of scars (Gärtner 2007). These features, usually in combination with geomorphological mappings, help to purely date natural hazard events to the year (Gärtner et al. 2003), but more detailed information such as the severity and type of mass movements has hardly ever been retrieved from reaction wood (Clague and Souther 1982).

Furthermore, dendrochronological reconstructions of geomorphic events have so far been mainly based on conifer wood, but comparable studies on angiosperms are rather scarce. Un-

${ }^{1}$ Author for correspondence; current address: Research Centre Jülich, 52425 Jülich, Germany; e-mail: i.heinrich@fz-juelich.de.

Manuscript received October 2007; revised manuscript received December 2007. like coniferous compression wood, angiosperm trees form tension wood as a direct response to a mechanical bending force, which causes eccentricity of an inclined stem due to enhanced growth on the upslope tension wood side in contrast to normal to reduced growth in the opposite wood on the downslope side (Scurfield 1973). The tension wood in European alder (Alnus glutinosa L. Gaertn.) and beech (Fagus sylvatica L.) is characterized by important structural modifications such as the presence of gelatinous fibers, low lignin, and high cellulose contents and a frequent reduction in vessel sizes and numbers. In contrast, the opposite wood on the downslope side exhibits lignin and cellulose contents comparable to those of normal wood, and it lacks gelatinous fibers (Clarke 1947; Archer 1986). However, tension wood in many species is difficult to detect macroscopically. Frequently, it is only distinguishable from normal wood by a silvery sheen visible on stem cross sections. Thus, tension wood can be easily missed during standard tree-ring analysis, especially when working on standard 4-mm core samples. Tension wood is usually identified in microscopic examinations in combination with specific dyes such as astra blue and safranin, which stain cellulose and lignin blue and red, respectively (Bland and Scurfield 1964; Côté and Day 1965; Hughes 1965). The form of tension wood has been found to be species dependent and related to the physiological status of the plants, parts of the plant affected, type and duration of the mechanical impact, and climatic conditions (Sachsse 1961; Wardrop 1964; Côté and Day 1965; Arganbright and Bensend 1968; Nicholson 1973; Nicholson et al. 1975). 
The general lack of studies on the use of tension wood for reconstructing geomorphic processes, in comparison to similar studies on compression wood (Gärtner 2007), is probably because it is difficult to detect without microscopic examination, and as a result of its high structural variability, Höster and Liese (1966) showed that some broadleaf species do not form tension wood at all. Consequently, a better comprehension of reaction wood formation in angiosperm trees caused by mechanical impacts is desirable. Angiosperm trees often occur in mixed forests together with conifers, and in lower elevations, they are the dominant species available for dendrogeomorphological reconstructions (Ellenberg 1996; Gärtner 2007). In addition, angiosperms have a more complex wood anatomy and offer structures (vessels and parenchyma) that are potentially useful for further analysis but are not found in coniferous wood (Timell 1986; Schweingruber et al. 2006).

Thus, a wood anatomical analysis of vessels in tension wood induced artificially as part of a growth experiment promises to obtain more complete information on the potentially different tree reactions. This study concentrated on two broadleaf species, European alder and beech. Both species are commonly found in European forests, and it has already been ascertained that they form tension wood (Höster and Liese 1966). Several studies have focused on fundamental reaction wood properties in alder (Wilson and Gartner 1996) and beech (Clair and Thibaut 2001), but an experimental approach imitating different geomorphic processes and analyzing their effects on wood anatomical properties of trees growing under natural conditions has not been tried yet.

This article aims to study whether different mechanical impacts will result in alterations of wood structural properties. We hypothesize that vessel lumen area (VLA) as a surrogate for tension wood severity in European alder and beech should be smaller; i.e., tension wood should be more intense, after more severe bending, and that tension wood formation should be altered if the tree is not just bent but also modified in other ways such as wounding in addition to bending.
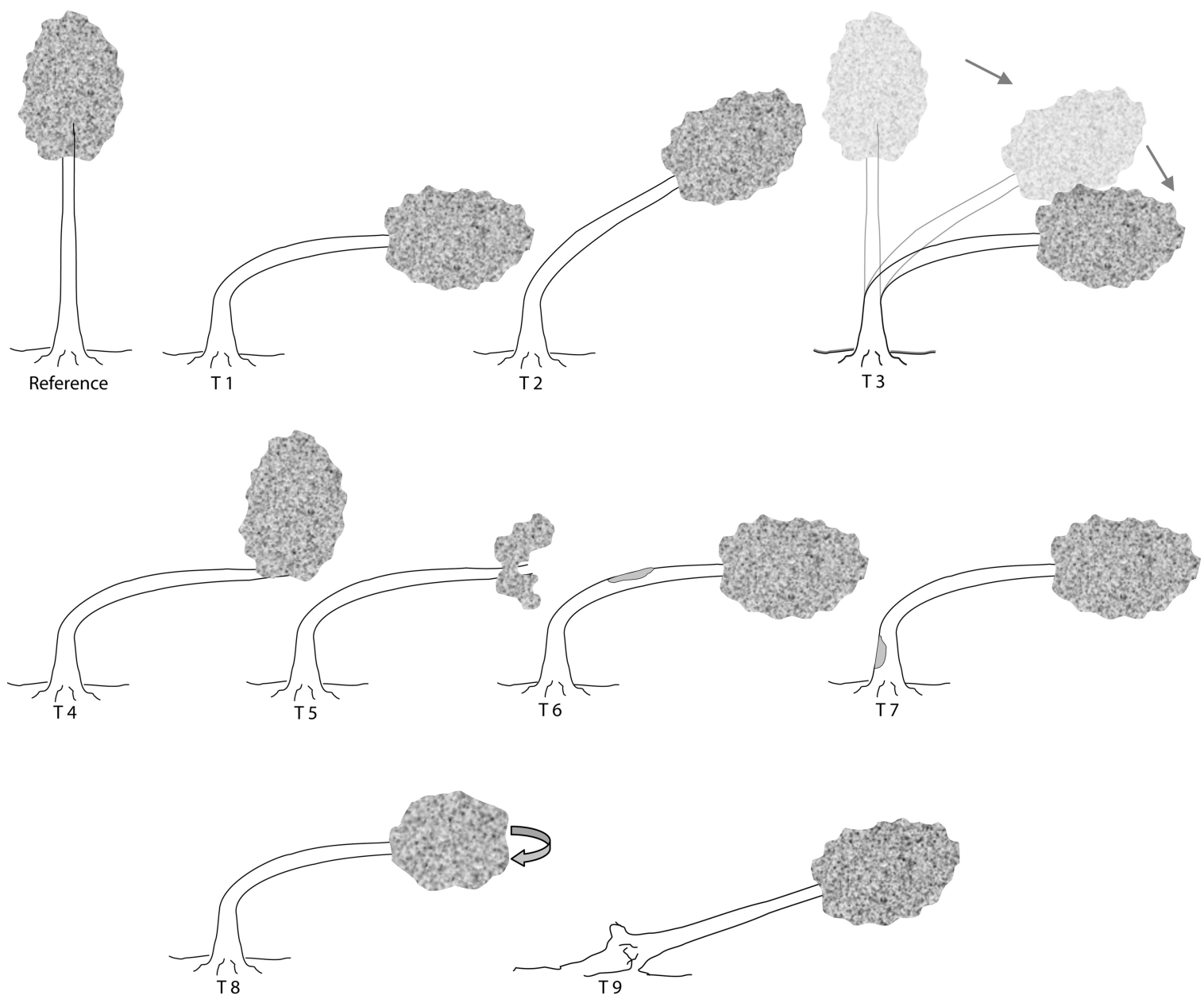

Fig. 1 Setup of the different treatment groups: T1 $=$ stem bent to $80^{\circ}$ from the vertical; T2 $=$ stem bent to $45^{\circ}$ from the vertical; T3 $=$ stem bent increasingly in time starting from small angles up to $80^{\circ}$; T4 $=$ stem bent to $80^{\circ}$ but with the apex remaining vertical; T5 $=$ stem bent to $80^{\circ}$ with apex cut; $\mathrm{T} 6=$ stem bent to $80^{\circ}$ but with the bark and cambium partly removed from the tension side of an upper stem section; T7 $=$ stem bent to $80^{\circ}$ but with the bark and cambium partly removed from the tension side of a lower stem section; T $8=$ stem bent to $80^{\circ}$ and sideways; $\mathrm{T} 9=$ stem bent to $80^{\circ}$ from the vertical with roots partly destroyed. 


\section{Material and Methods}

In Switzerland, we set up growth experiments with European alder near Fribourg $\left(7^{\circ} 08^{\prime} \mathrm{N}, 46^{\circ} 45^{\prime} \mathrm{W}, 600 \mathrm{~m}\right.$ a.s.l.) and with European beech near Interlaken $\left(7^{\circ} 45^{\prime} \mathrm{N}, 46^{\circ} 38^{\prime} \mathrm{W}, 840 \mathrm{~m}\right.$ a.s.1.) in October 2004. The forest stand near Interlaken contains beech regrowth, which developed following heavy storm damage, and the forest stand of alder was planted near Fribourg $\sim 12$ yr ago. At both sites, we mainly treated young trees (10-20 yr old), which were flexible enough to be bent to $80^{\circ}$ without breaking the stem (diameters $4-10 \mathrm{~cm}$ ). At both sites, nine different treatment groups (T1 to T9) and one untreated reference group $(\mathrm{R})$ were set up, each group containing four trees per species. In all treatment groups, except for T2 and $\mathrm{T} 3$, the trees were bent to $80^{\circ}$ from the vertical. In group $\mathrm{T} 1$, the bending remained the only treatment, whereas in T4 to T9, additional treatments were applied (fig. 1).
Some of these treatments were inspired by experiments conducted by others. For example, Robards (1966) investigated the degree of eccentricity and amount of tension wood formed in willow (Salix fragilis L.), depending on the angle of displacement from the vertical. Likewise, in this study, groups T1 to T3 compared the reactions due to the different angles of displacement. Trees in group T4 were bent to $80^{\circ}$, while the apex of the trees remained vertical. In group T8, the trees were bent to $80^{\circ}$ and had their crowns bent sideways. In similar experiments, Wardrop (1964) also tilted various eucalyptus species into the horizontal, but the upper parts of the crowns were pushed back into the vertical. Our experiments T4 and T8 reproduced the situation of trees being bent because of a mass movement, but with the upper parts of their crowns leaning against obstacles, thus staying vertical or being bent sideways. We also set up group T5, a variety of T4, i.e., the apex of the trees were cut. This treatment imitated
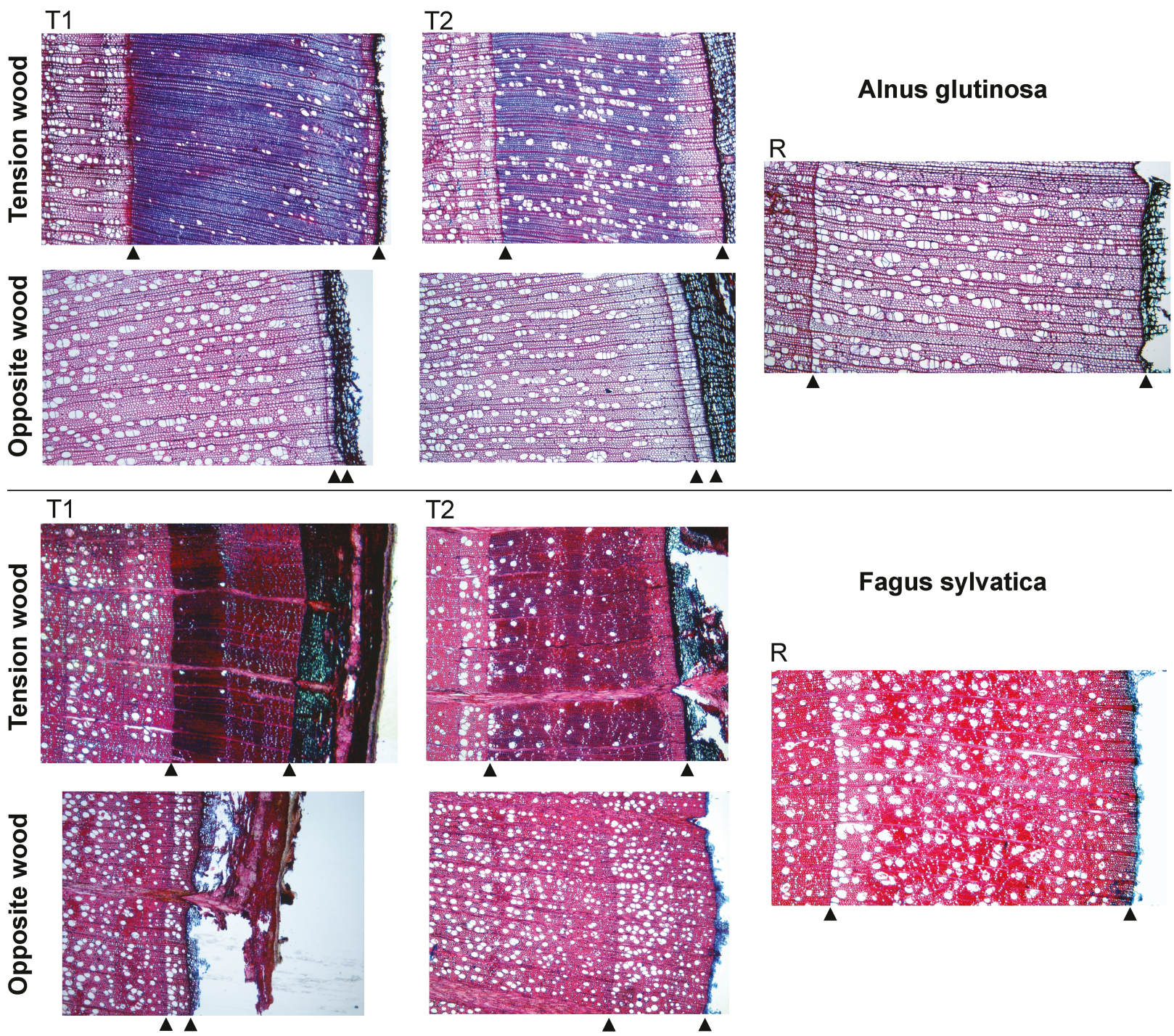

Fagus sylvatica

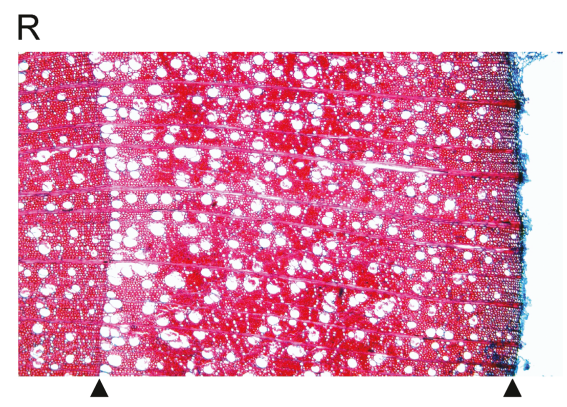

Fig. 2 Visual comparison of microscopic cross sections from the tension wood and opposite wood side in Alnus glutinosa (top) and Fagus sylvatica (bottom); from left to right: treatment T1, T2, and reference group R (magnification: $\times 40$ ). Black triangles indicate tree-ring width of the year measured. 

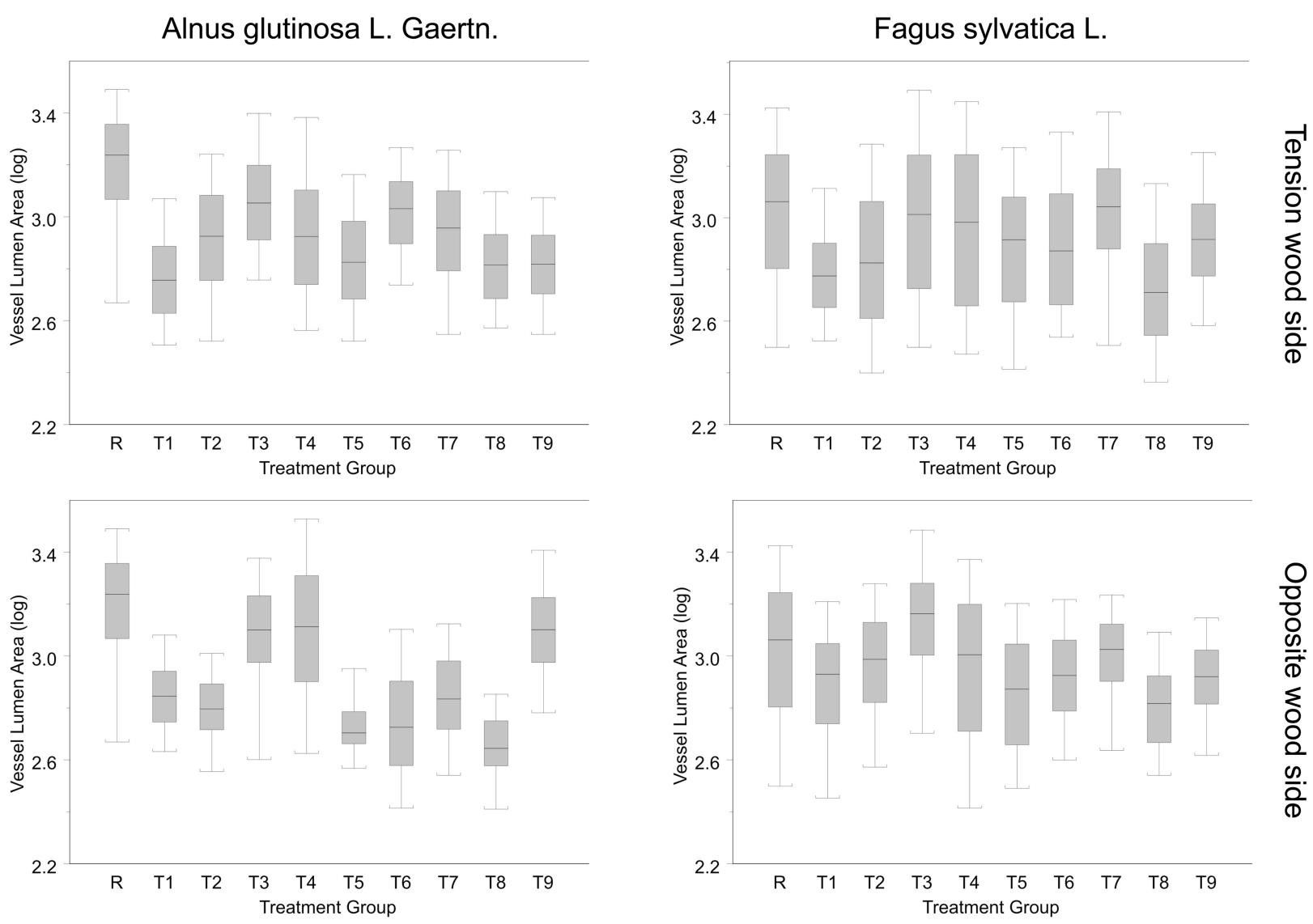

Fig. 3 Vessel lumen area (log-transformed) per treatment (T1-T9) and reference group R at tension wood side (upper row) and opposite wood side (lower row) for alder (left) and beech (right).

the case when a tree, affected by a mass movement, was bent heavily and additionally lost its crown.

In a further study, Wardrop (1956) tested the hypothesis that partly removing the bark from the upper side of a leaning tree results in altered reaction wood in different eucalyptus species. This scenario, which we simulated in group T6, happens when a tilted tree is also damaged during a mass movement event. In addition, we included group T7 to test whether the removal of the bark and cambium from the lower part of the tree would result in a reaction different from that of T6. In group T9, we tilted the trees to $80^{\circ}$ and partly destroyed the roots, which in reality occurs when the affected trees are less flexible and the major mechanical force is absorbed by the roots.

The treatments were maintained for the entire growing period in 2005. In November 2005, i.e., after growth had fully ceased, the stems of four trees per treatment group were collected, altogether 40 trees per species.

The stem sections of all trees containing parts prone to potential tension wood formation were sawed and transverse $15-\mu \mathrm{m}$ microsections of the tension wood side and the opposite wood side were cut with a sliding microtome and stained using astra blue and safranin according to standard techniques (Schweingruber 2001).

A Zeiss Axioskop equipped with a digital camera was used to conduct light microscopy, and photos of the sections in various magnifications were taken. Cross-sectional vessel sizes were measured and recorded by means of digital imagery using the software program WinCELL Pro 2005a. Within this software program, a measuring frame of constant width $(4 \mathrm{~mm})$ but varying length, adjusting for the different ring widths, was used to measure vessel sizes in the 2005 tree ring. The adjustment was necessary because ring widths varied immensely,

Table 1

\begin{tabular}{|c|c|c|}
\hline $\begin{array}{r}\text { Number of Me } \\
\text { Vessel Lume } \\
\text { Wood Sid } \\
\text { (OS) }\end{array}$ & $\begin{array}{l}\text { red Cells and } \\
\text { rea (VLA) Sep } \\
\text { rWS) and Opp } \\
\text { European Alde }\end{array}$ & $\begin{array}{l}\text { Its of ANOVA for } \\
\text { ed into Tension } \\
\text { Wood Side } \\
\text { d Beech }\end{array}$ \\
\hline $\begin{array}{l}\text { Species/sample } \\
\text { location }\end{array}$ & Vessel counts & $\mathrm{VLA}^{\mathrm{a}}$ \\
\hline Alder: & & \\
\hline TWS & 9232 & $590.2674 / .0001$ \\
\hline OS & 6504 & $347.7683 / .0001$ \\
\hline Sum & 15,736 & \\
\hline Beech: & & \\
\hline TWS & 9048 & $110.9784 / .0001$ \\
\hline OS & 6649 & $91.80636 / .0001$ \\
\hline Sum & 15,697 & \\
\hline Total & 31,433 & \\
\hline
\end{tabular}

a $F$ value $/ P(F)$. 
Alnus glutinosa L. Gaertn.
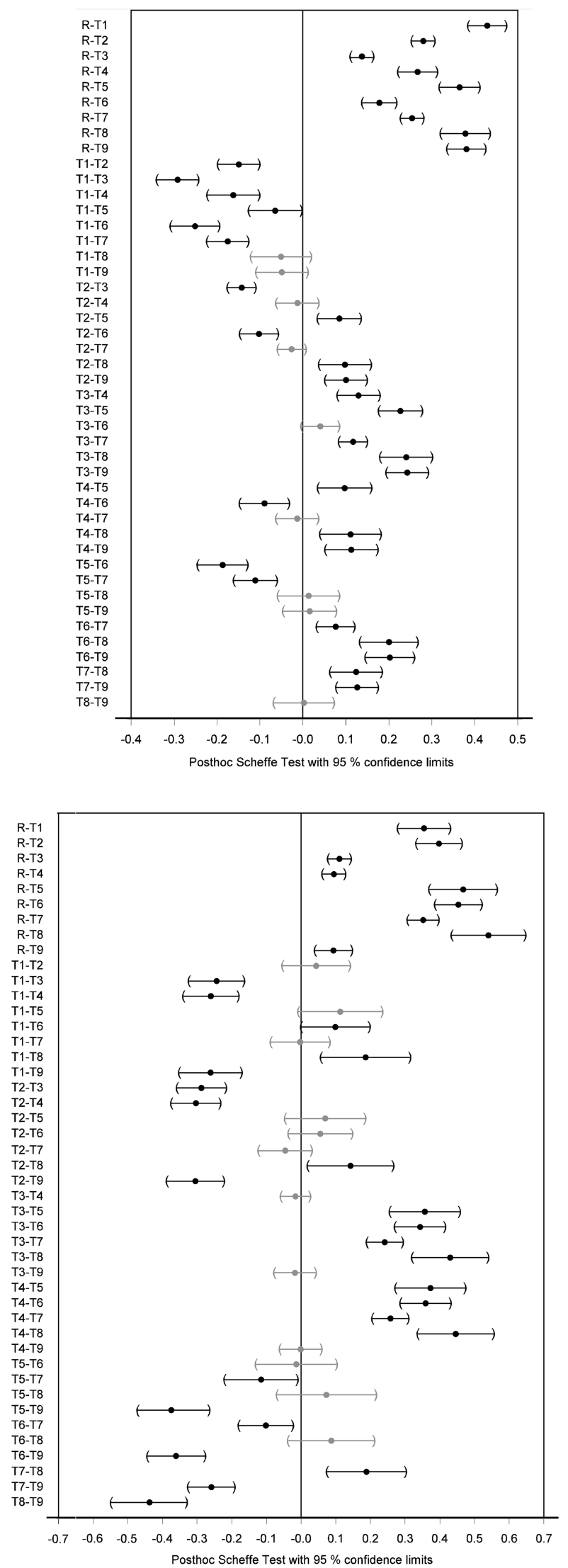

Fagus sylvatica L.

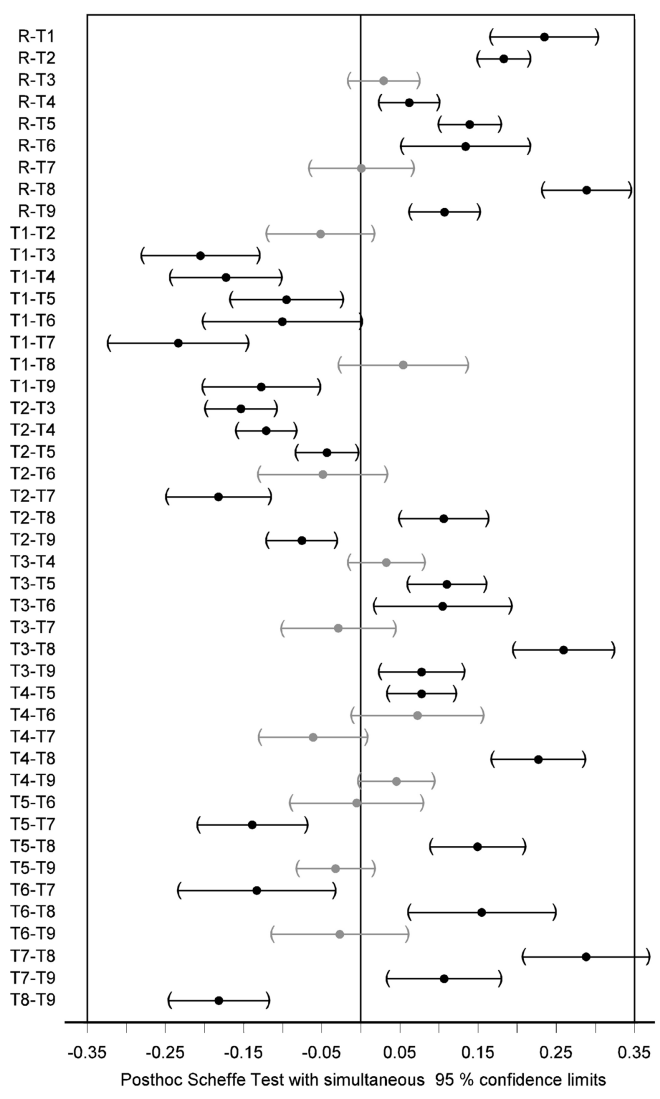

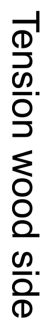

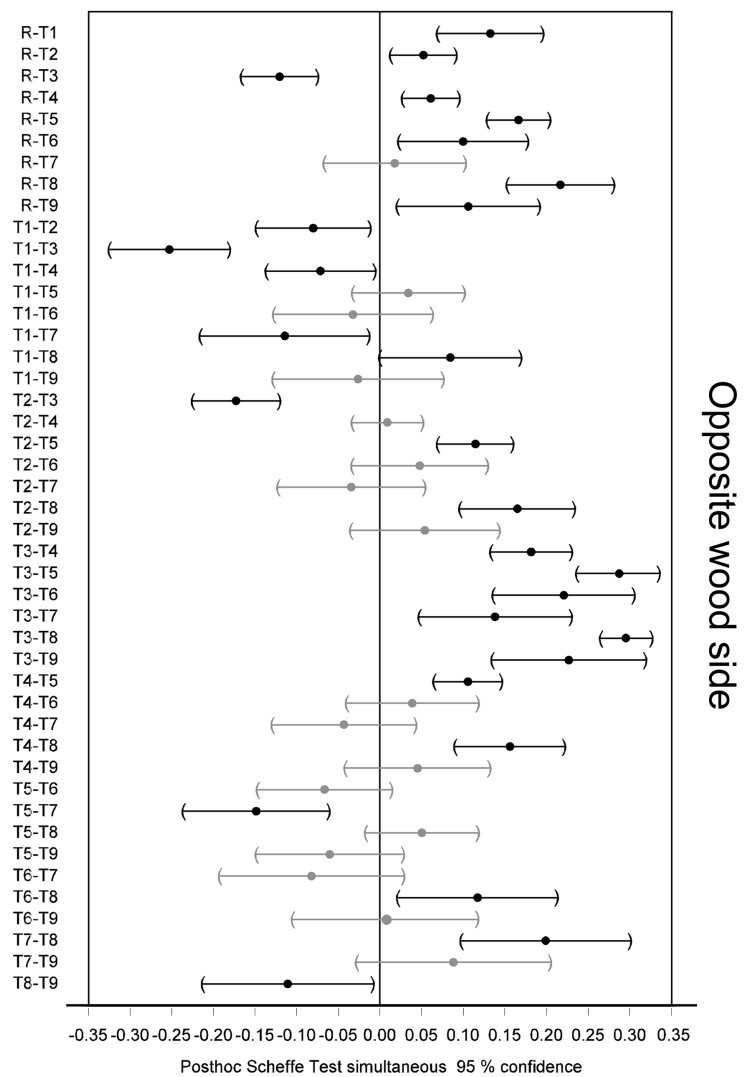


and therefore a measuring frame of fixed size was not feasible. However, this study was not so much concerned with the amount of vessels or VLA in relation to the entire crosssectional area but only interested in the different vessel sizes present in the entire tree-ring widths of the tension wood and opposite wood zones. This is why the measuring frame was always adjusted for the individual tree-ring widths of the respective zones. The software uses an algorithm to compute VLA of the vessels individually found within the measurement frame. The object recognitions and measurements were carried out automatically, but each analysis was checked visually by the operator and, if necessary, corrected manually.

The resulting data were used to investigate quantitatively the influence of the different treatments. All statistical analyses were carried out in S-PLUS 6.0 Professional Release 1, starting with an assessment of the normality of the data using histograms. The distribution of the data was skewed and had to be log-transformed to conform to a normal distribution before further analysis could be applied. The S-PLUS diagnostic plots, e.g., residual plots and Cook's distance, were used to ensure constant variance and absence of outliers, respectively (Cook and Weisberg 1999). For a graphical examination of the variations in VLA between the treatment groups, boxwhisker plots were created. ANOVA was conducted to test their variances between and within groups R and T1 to T9. For an a posteriori examination, the relatively rigorous and robust post hoc Scheffé test was selected because of the large number of measurements and variation in sample size of measured vessels.

\section{Results and Discussion}

The visual comparison of microsections prepared from tree stems of European alder and beech illustrates that both species developed tension wood due to bending stress in treatment groups T1 (bent to $80^{\circ}$ ) and T2 (bent to $45^{\circ}$ ) compared with the untreated reference group R (fig. 2). In addition, trees in treatment group T1 formed more intense tension wood than trees in T2. Visually, the higher intensity in T1 on the tension wood side is characterized by darker blue to violet colors. The underlying wood anatomical changes are fewer and smaller vessels and smaller tension wood fibers with thicker cell walls and gelatinous layers (stained blue). The visual inspection also reveals that both species when severely bent in T1 show very few vessels in the early part of the tree ring, which suggests, in agreement with biomechanical literature (Mattheck and Kubler 1997), that the trees first tried to stabilize and then facilitated supply with nutrients and water. Furthermore, the comparison of the microsections cut from the tension wood side and opposite wood side points out the dissimilar growth increments formed in both species during the experiment. This unequal growth, i.e., small on the opposite wood side and large on the tension wood side, results in stem eccentric- ity, which has often been used for dendrogeomorphological dating purposes (Shroder 1980). The growth increments on the opposite wood side are smaller in T1 than T2 (fig. 2), which eventually will lead to more severe stem eccentricity as a result of the stronger bending intensity in T1. The comparison demonstrates that stem eccentricities of varying strength might be expected in angiosperms because of different bending, as has been suggested for conifers (Duncker and Spiecker 2005).

Similarly, the measurements presented as box-whisker plots (fig. 3), ANOVA (table 1), and post hoc Scheffé test (fig. 4) for VLA on the tension wood side and the opposite wood side confirm the trends for both species gained from the first visual impressions.

The ANOVA procedure has resulted in high $F$ values with low $P$ values approaching zero (table 1 ). These extreme values are partly due to the large sample size with relatively little variation of the measured values within the treatment groups. Nevertheless, it can be inferred that the variation is significantly larger between than within the treatment groups.

Both species exhibit the largest values for VLA in the reference group (R) which illustrates that the treatments were generally successful in inducing tension wood (figs. 3, 4). The data also show that VLA decreases from T3 (increased bending) to T1 (bent to $80^{\circ}$ ). In alder and beech, out of all treatments, T1 has resulted in the strongest declines in VLA on the tension wood side, with the exception of T8, which has similarly low values. This strong reduction in VLA indicates that variations in VLA might be used not only to date past mechanical impacts but also to reconstruct them in more detail. Similarly, Yanosky (1984) used different forms of so-called flood rings, characterized by various alterations to the typical ring-porous tree-ring structure of ash trees (Fraximus americanum L. and F. pennsylvanica Marsh.) growing along the Potomac River to reconstruct past flood events. Our study corroborates the results of Yanosky (1984) that cross-sectional vessel dimensions not only change because of mechanical or similar environmental stresses but are also sensitive to the severity of the impact.

Further, our findings support results from studies conducted on crack willow (Robards 1966) and red alder (Alnus rubra Bong.; Wilson and Gartner 1996). Both studies concluded that the intensity in tension wood is related to degree of lean from the vertical. The results imply that a good potential exists to differentiate tension wood into severity classes, which in our case were caused by treatments imitating different mass movement intensities. Comparable approaches to identify compression wood severity classes have already been advanced for conifers (Yumoto et al. 1983) but not yet for tension wood in angiosperms. However, more studies on tension wood such as this study are needed before reliable severity classes can be developed for angiosperms.

The comparisons between the other treatment groups show that VLA is larger in T4 (bent to $80^{\circ}$ and apex vertical) than

Fig. 4 Post hoc Scheffé test for vessel lumen area (log-transformed) per treatment (T1-T9) and reference group R at tension wood side (upper row) and opposite wood side (lower row) for alder (left) and beech (right); black and gray symbols indicate significant and insignificant differences, respectively; pairs of treatments compared are significantly different if the confidence limits do not touch the vertical zero line in the middle. 
in T5 (bent to $80^{\circ}$ and apex cut) and T8 (bent to $80^{\circ}$ and apex sideways). VLA is also significantly larger in T9 (bent to $80^{\circ}$ and roots partly destroyed) than in $\mathrm{T} 1$ (bent to $80^{\circ}$ ) in beech on the tension wood side and in alder on the opposite wood side. These differences suggest that the treatments in T1 to T3 were not only successful in inducing tension wood of different intensities in both species but also in affecting the tension wood formation in the remaining treatment groups T4 to T9 due to the additional treatments such as removal of the apex. In both alder and beech, e.g., VLA on the tension wood side decreased less in T5 and T4 (apex cut and bent into the vertical, respectively) than in T1, but in T8, VLA was as low as in T1 (figs. 3, 4). Comparing T1 with T4 to T5 and T8, it seems that the tension wood is less severe when the apex remains vertical or when it is removed, but the tension wood remains severe as long as the apex stays horizontal no matter whether it is also bent sideways. This result is in agreement with conclusions drawn from experiments in which stems and branches were bent into vertical and horizontal loops. It was demonstrated that the position of the upper stem part seems to be important for trees to react to gravitational forces (Jaccard 1938; Hartmann 1942). Furthermore, Wardrop (1956, 1964) found that the reaction wood was less intensive in bent eucalyptus when their apex remained vertical, when plants were placed on a horizontal clinostat, or when the apex was cut after the trees were bent into the horizontal position, which was also the case in our study.

In alder, VLA on the tension wood side is significantly larger in group T6 (bent to $80^{\circ}$ and cambium damaged at upper stem section) than $\mathrm{T} 7$ (bent to $80^{\circ}$ and cambium damaged at lower stem section). Similarly, Wardrop (1956) concluded that the removal of the bark from the upper part resulted in less intense tension wood formation in eucalyptus compared with more intense tension wood when the bark was removed on the lower side, but in this study in beech, the opposite occurred. In comparison, VLA is significantly lower in T1 (bent to $80^{\circ}$ ) than in $\mathrm{T} 9$ (bent to $80^{\circ}$ and roots partly destroyed) on the opposite wood side in alder and on the tension wood side in beech, which suggests that the two species react differently to mechanical stress; i.e., the signal for the gravitational response might be generated by different parts of the plant in beech and alder (Wayne and Staves 1997). Recent research results (Sahling 2007; Hitz et al. 2008) also suggest that the reactions to mechanical stresses might be species specific. While Sahling (2007) concluded that changing vessel dimensions in beech roots were more reliable indicators of root exposure after soil erosion, Hitz et al. (2008) found that fibers in ash roots are more suitable for this purpose.

The overall results for VLA on the opposite wood side are similar to the tension wood side (figs. 3,4 ). The exceptions to the tension wood in alder are that T1 is not significantly different from T2, and T6 is significantly smaller than T7. In beech, T9 is not significantly different from T1. Nevertheless, the results for the opposite wood side show that not only the vessels formed in the tension wood but also in the opposite wood are affected by the different treatments. Hence, VLA not only of the tension wood side but also of the opposite wood side might be used for the detection of mechanical impacts. In extreme instances of mechanical stress, the wood production on the opposite wood side was very small and the analysis was limited then, and thus we conclude that dendrogeomorphological research should concentrate on the tension wood side. However, if in some cases trees that have been affected by mass movements such as avalanches or debris flows are leaning downhill and have lost most of their bark and cambium on the uphill stem part, that is, the place of tension wood formation, the wood analysis of the opposite wood side might be the only option (Butler and Malanson 1985; Fantucci 1999).

These study results might also be relevant to related research in dendroclimatology in which cross-sectional vessel dimensions are used as proxies for climate reconstructions. Several studies have shown that vessel sizes of various tree species are good indicators of climatic factors such as water availability (Sass and Eckstein 1995; Eilmann et al. 2006), temperature (Fonti and García-González 2004), and precipitation (Heinrich and Banks 2006). Our results, though, indicate that vessel dimensions are also sensitive to mechanical stresses. In dendroclimatology, stem zones potentially containing tension wood are usually avoided by collecting samples parallel to the contour lines (Cook and Kairiukstis 1990). However, tension wood is difficult to recognize macroscopically and hence can be easily overlooked during normal tree-ring analysis. Undetected tension wood can occur temporarily anywhere along a tree stem due to, e.g., changed internal statics, wind sway, or competition for sunlight (Schweingruber 1996) and might interfere with climate reconstructions based on vessel measurements.

Overall, the project has illustrated that the application of wood anatomical techniques to vessels can provide supplementary information about type and intensity of past mechanical impacts on angiosperm tree growth. Modern dendrogeomorphology needs to combine both tree-ring analysis and wood anatomy, warranting reliable reconstructions of different geomorphic events. Angiosperms have a more complex wood structure than conifers and thus possess alternative anatomical features that can provide additional information regarding the severity of the impact. Furthermore, the simple advantage of VLA over fiber and tracheid lumen areas is that vessels are larger and, therefore, easier to measure even without preparing microsections (Fonti and García-González 2004). However, not all angiosperms seem to form tension wood in stems; Onaka (1949) found that only $61 \%$ of the examined angiosperms formed tension wood. Similar numbers $(64 \%)$ were presented by Nečesaný (1955) and by Höster and Liese (1966), which showed that in angiosperms tension wood can be found in only $50 \%$ of the branches and $25 \%$ of the roots.

In future applications, these observations might pose a problem when using intensities in tension wood of some angiosperms for reconstructing mass movements. But once it has been established that a certain angiosperm tree species forms tension wood, it can be used for further detailed studies on mass movements. It seems that although until now dendrogeomorphic research has mainly concentrated on using conifer trees for the reconstruction of mass movements, angiosperm trees are at least equally suitable for such investigations. We propose that future research should also include angiosperms in order to obtain more detailed descriptions of mass movements. 


\section{Acknowledgments}

We wish to thank the Swiss National Science Foundation for project funding (project 200021-101668/1) and Michel
Monbaron for his support throughout the project. We would like to express our gratitude to the local foresters, Beat Zurbuchen (Krattigen) and Jacques Galley (Fribourg), for their help during site selection.

\section{Literature Cited}

Alestalo J 1971 Dendrochronological interpretation of geomorphic processes. Fennia 105:1-140.

Archer RR 1986 Growth stresses and strains in trees. Springer, Berlin. Arganbright DG, DW Bensend 1968 Relationship of gelatinous fiber development to tree lean in soft maple. Wood Sci 1:37-40.

Bland DE, G Scurfield 1964 The chemistry of reaction wood. IV. The distribution and nature of the lignin in seedlings of hardwoods. Holzforschung 18:161-166.

Butler DR, GP Malanson 1985 A reconstruction of snow-avalanche characteristics in Montana, U.S.A., using vegetative indicators. J Glaciol 31:185-187.

Clague JJ, JG Souther 1982 The dusty creek landslide on Mount Cayley, British Columbia. Can J Earth Sci 19:524-539.

Clair B, B Thibaut 2001 Shrinkage of the gelatinous layer of poplar and beech tension wood. IAWA J 22:121-131.

Clarke SH 1947 Distribution, structure and properties of tension wood in beech (Fagus sylvatica L.). Forestry 11:85-91.

Cook ER, LA Kairiukstis 1990 Methods of dendrochronology: applications in the environmental sciences. Kluwer, Dordrecht.

Cook RD, S Weisberg 1999 Applied regression including computing and graphics. Wiley, Hoboken, NJ.

Côté WA, AC Day Jr 1965 Anatomy and ultrastructure of reaction wood. Pages 391-418 in WA Côté, ed. Cellular ultrastructure of woody plants. Syracuse University Press, Syracuse, NY.

Duncker P, H Spiecker 2005 Compression wood formation and pith eccentricity in Picea abies L. depending on selected site-related factors: detection of compression wood by its spectral properties in reflected light. Pages 150-158 in H Gärtner, J Esper, G Schleser, eds. TRACE— tree rings in archaeology, climatology and ecology. Vol 3. Schriften des Forschungszentrums Jülich-Reihe Umwelt 53.

Eilmann B, P Weber, A Rigling, D Eckstein 2006 Growth reactions of Pinus sylvestris L. and Quercus pubescens Willd. to drought years at a xeric site in Valais, Switzerland. Dendrochronologia 23: $121-132$.

Ellenberg H 1996 Vegetation Mitteleuropas mit den Alpen. Eugen Ulmer, Stuttgart.

Fantucci R 1999 Dendrogeomorphology in landslide analysis. Pages 69-81 in R Casale, C Margottini, eds. Floods and landslides. Springer, Berlin.

Fonti P, I García-González 2004 Suitability of chestnut earlywood vessel chronologies for ecological studies. New Phytol 163:77-86.

Fritts HC 1976 Tree rings and climate. Blackburn, Caldwell, NJ.

Gärtner H 2007 Glacial landforms, tree rings: dendrogeomorphology. Pages 979-987 in SA Elias, ed. Encyclopedia of Quaternary sciences. Vol 2. Elsevier, Amsterdam.

Gärtner H, M Stoffel, I Lièvre, M Monbaron 2003 Tree ring analyses and detailed geomorphological mapping on a forested debris flow cone in Switzerland. Pages 207-217 in D Rickenmann, C Chen, eds. Debris flow hazards mitigation: mechanics, prediction, and assessment. Proceedings of the Third International Conference on DebrisFlow Hazards Mitigation. Millpress, Rotterdam.

Hartmann F 1942 Das statische Wuchsgesetz bei Nadel- und Laubbäumen. Neue Erkenntnis über Ursache, Gesetzmäßigkeit und Sinn des Reaktionsholzes. Springer, Vienna.

Heinrich I, JCG Banks 2006 Variation of phenology, tree growth, and wood anatomy of Toona sinensis and Toona ciliata in relation to different environmental conditions. Int J Plant Sci 167:831-841.

Hitz OM, H Gärtner, I Heinrich, M Monbaron 2008 First time application of ash (Fraxinus excelsior L.) roots to determine erosion rates in mountain torrents. Catena 72:248-258, doi:10.1016/j.catena 2007.05.008.

Höster HR, W Liese 1966 Über das Vorkommen von Reaktionsgewebe in Wurzeln und Ästen der Dikotyledonen. Holzforschung 20: 80-90.

Hughes FE 1965 Tension wood: a review of literature. II. For Abstr 26:179-186.

Jaccard P 1938 Exzentrisches Dickenwachstum und anatomischhistologische Differenzierungen des Holzes. Ber Schweiz Bot Ges 48:491-537.

Leavitt SW 1993 Seasonal ${ }^{13} \mathrm{C} /{ }^{12} \mathrm{C}$ changes in tree rings: species and site coherence, and a possible drought influence. Can J For Res 23: 210-218.

Mattheck C, H Kubler 1997 Wood-the internal optimization of trees. Springer, Berlin.

Nečesaný V 1955 Vyskyt reakcniho dreva s hlediska taxonomickeho: Sbornik Vysoke Skoly zemedelske a lesnicke fakulty. Rada C 3: 131-149.

Nicholson JE 1973 Growth stress differences in eucalypts. For Sci 19: 169-174.

Nicholson JE, WE Hillis, N Ditchburne 1975 Some tree growthwood property relationships of eucalypts. Can J For Res 5:424-432.

Onaka F 1949 Studies on compression and tension wood. Wood Res 24:1-88.

Robards AW 1966 The application of the modified sine rule to tension wood production and eccentric growth in the stem of crack willow (Salix fragilis L.). Ann Bot 30:513-523.

Sachsse H 1961 Untersuchungen über Eigenschaften und Funktionsweise des Zugholzes der Laubbäume. J-D Sauerländer, Frankfurt.

Sahling I 2007 Rekonstruktion geomorphologischer Prozessabläufe unter Verwendung dendrogeomorphologischer Methoden und der holzanatomischen Analyse von Jahrringen in Buchenwurzeln. PhD diss. Martin-Luther-University, Halle-Wittenberg, Halle, Germany.

Sass U, D Eckstein 1995 The variability of vessel size in beech (Fagus sylvatica L.) and its ecophysiological interpretation. Trees 9:247252.

Schweingruber FH 1996 Tree rings and environment: dendroecology. Swiss Federal Institute for Forests, Snow and Landscape Research, Birmensdorf, and Paul Haupt, Bern.

2001 Dendroökologische Holzanatomie: Anatomische Grundlagen der Dendrochronologie. Swiss Federal Institute for Forests, Snow and Landscape Research, Birmensdorf, and Paul Haupt, Bern. Schweingruber FH, A Börner, E-D Schulze 2006 Atlas of woody plant stems: evolution, structure, and environmental modifications. Springer, Berlin.

Scurfield G 1973 Reaction wood: its structure and function. Science 179:647-655.

Shroder J Jr 1980 Dendrogeomorphology: review and new techniques of tree-ring dating. Prog Phys Geogr 4:161-188.

Timell TE 1986 Compression wood in gymnosperms. Springer Wood Series. Springer, Heidelberg. 
Wardrop AB 1956 The nature of reaction wood. Aust J Bot 4:152-166. 1964 Reaction anatomy of arborescent angiosperms. Pages 405-456 in MH Zimmermann, ed. Formation of wood in forest trees. Academic Press, New York.

Wayne R, MP Staves 1997 A down-to-earth model of gravisensing. Gravit Space Biol Bull 10:57-64.

Wilson BF, BL Gartner 1996 Lean in red alder (Alnus rubra): growth stress, tension wood, and righting response. Can J For Res 26:1951-1956.
Yanosky TM 1984 Documentation of high summer flows on the Potomac River from the wood anatomy of ash trees. Water Resour Bull 20:241-50.

Yumoto M, S Ishida, K Fukazawa 1983 Studies on the formation and structure of the compression wood cells induced by artificial inclination in young trees of Picea glauca. IV. Gradation of the severity of compression wood tracheids. Res Bull Coll Exp For 40: 409-454. 